\title{
Intensity of the Earth's Magnetic Field in Geological Time
}

\section{Pleistocene and Pliocene Data from Japanese Volcanic Rocks*}

\author{
Masaru Kono \\ Geophysical Institute, University of Tokyo
}

(Received September 18, 1970)

\begin{abstract}
Thellier's Method was applied to rocks obtained from several volcanic formations in Japan, of which geology has already been studied in detail. Owing to unstable nature of remanent magnetization and other effects in heating experiments, most of the Pliocene rocks did not give any meaningful results. Samples from Pleistocene lavas show more favorable behaviors in experiments. In all, 9 Pleistocene and 4 Pliocene intensity values were obtained. Of these, Pliocene values except for intermediate polarity are nearly the same as and Pleistocene values are much larger than the present magnitude of the geomagnetic field.
\end{abstract}

\section{Introduction}

Recently, the double heating method initiated by Thelliers (Thellier and Thellier, 1959) has widely been applied to natural volcanic rocks to obtain the magnitude of the earth's magnetic field in the remote past (Smith, 1967a, b, 1968). Although other methods have been proposed and used by several authors to determine paleointensities, the superiority of Thelliers' method is quite clear since it has a definite physical basis and also it reproduces the original magnetization acquisition process in a laboratory.

We have been trying to obtain reliable paleointensity values in these years and already reported some results of Thelliers' method applied to volcanic rocks of Japan and U.S.A. (Kono and Nagata, 1968; Kono, 1968). In the present paper, several additional determinations of paleointensities on Japanese volcanic rocks are reported. Samples were collected from Pleistocene and Pliocene volcanic fields where the geology of the rocks are already reported in detail (Fig. 1). Experimental procedures in this study is the same as those described in Kono and Nagata (1968).

For the sake of brevity, results of a.c. demagnetization of natural remanent magnetization (NRM) and of thermomagnetic and X-ray analyses of the ferromagnetic crystals are not discussed in detail but briefly summarized here. Stability of NRM to a.c. demagnetization differs considerably from unit to unit, but in the case of the present samples, the stability of NRM quite well corresponds to the dispersion of direction of magnetization ( $\alpha_{95}$ in the following table); samples of a stable unit show a tight grouping of NRM directions (small $\alpha_{95}$ ) which do not change significantly on application of a.c.

* Contribution from Division of Geomagnetism and Planetary Physics, Geophysical Institute, University of Tokyo, Series II, No. 288. 


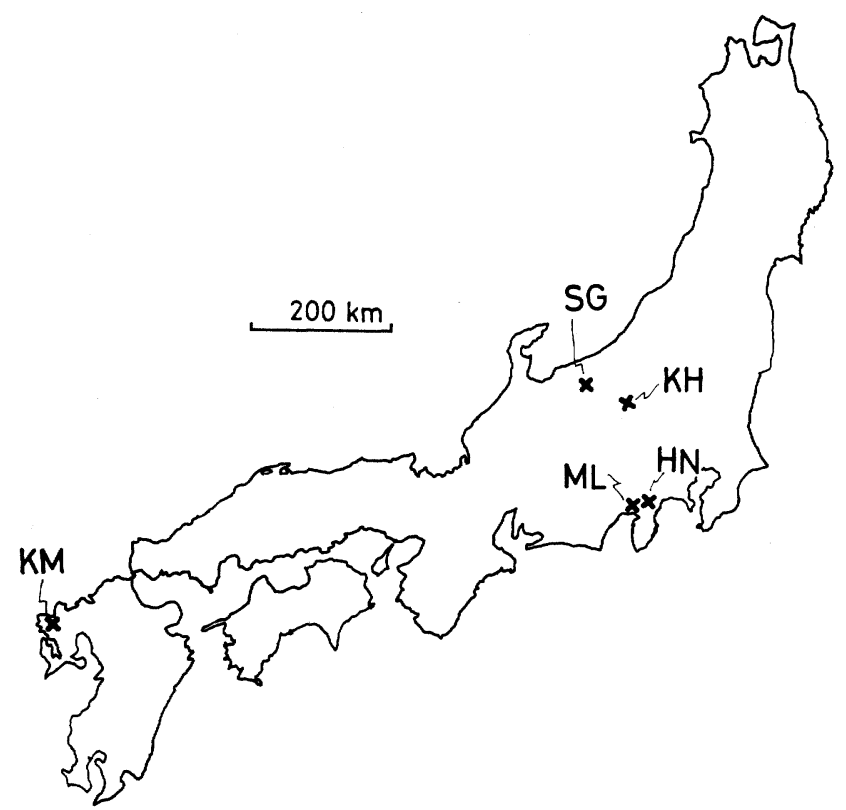

Fig. 1 Sampling Locations. ML: Mishima lava, HN: Hakone Nagao-toge lavas, SG: Shigarami formation, KM: KitaMatsuura basalts, KH: Kirizumi and Hanamagari formations.

field, while in unstable samples dispersions both before and after a.c. demagnetization are always large. It seems that large directional changes observed in demagnetization do not improve the grouping. The main part of ferromagnetic minerals always have a cubic structure with lattice parameter of about $8.40 \mathrm{~A}$ and have Curie point in the range $500-580^{\circ} \mathrm{C}$, indicating a composition very near to magnetite. Only a few of the samples show the presence of small amount of the second magnetic phase with a lower Curie point $\left(200-400^{\circ} \mathrm{C}\right)$.

\section{Mishima Lava of Mt. Fuji (ML)}

Mt. Fuji was formed in three stages of volcanic activities in Pleistocene, i.e., Komitake, Older Fuji and Younger Fuji Volcanoes (Tsuya, 1968). The lava flow sampled at Shimotokari, Mishima City, Shizuoka Prefecture is one of the oldest ejecta of the Younger Fuji called Mishima Lava Flows, widely distributed on the southwestern flank of the mountain. The age of this lava is considered to be about several tens of thousands of years (H. Kuno, personal communication). The uppermost ten meters of this lava is exposed on the surface. The magnetic properties of the rocks show a considerable change with depth from the top (Ohnaka, 1969). Samples were collected at different depths in the lava in order to investigate if the same results can be obtained from rocks which cooled at the same time and place but with different magnetic properties.

Results of the experiments are illustrated in Fig. 2 and summarized in Table 1. 


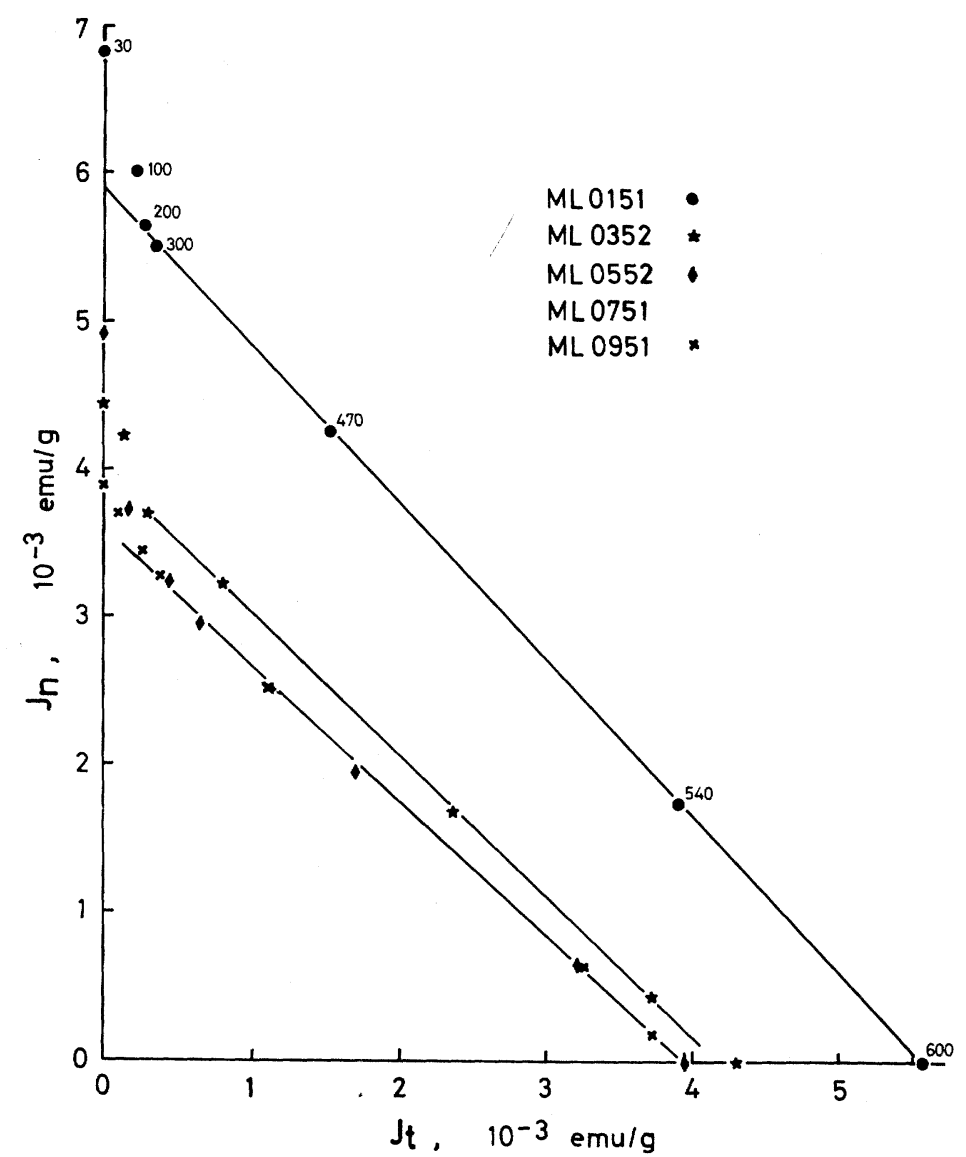

Fig. $2 J_{n}-J_{t}$ diagram of ML specimens. Numbers in the figure indicate the temperature in ${ }^{\circ} \mathrm{C}$.

Among the five specimens, the one at 7.5 meters from the top surface showed an irregular curve in the $J_{n}-J_{t}$ diagram and intensity could not be estimated. According to Ohnaka (1969), changes of magnetic properties such as $\chi$ and $H_{c}$ are observed at about 7 meters in this lava. However, it is not certain if these changes are related to the failure of intensity experiments. Satisfactorily linear $J_{n^{-}} J_{t}$ curves were obtained from the other four specimens, though the points for temperatures $30^{\circ} \mathrm{C}$ and $100^{\circ} \mathrm{C}$ show departures from the straight lines. This may be due to viscous remanent magnetization (VRM) imposed by the geomagnetic field on the original magnetization.

The good agreement of intensities between different specimens show that paleointensities may not be affected by the difference of ferromagnetic minerals in rocks. This is also in accord with the results obtained by Coe (1967 a) for baked sediment and overlying basalt in northeastern California. The selection of specimens for paleointensity studies may, therefore, be made from the viewpoint of magnetic stability of original NRM and chemical stability of ferromagnetic minerals in heating experiments. 
Table 1. Direction and Intensity Data

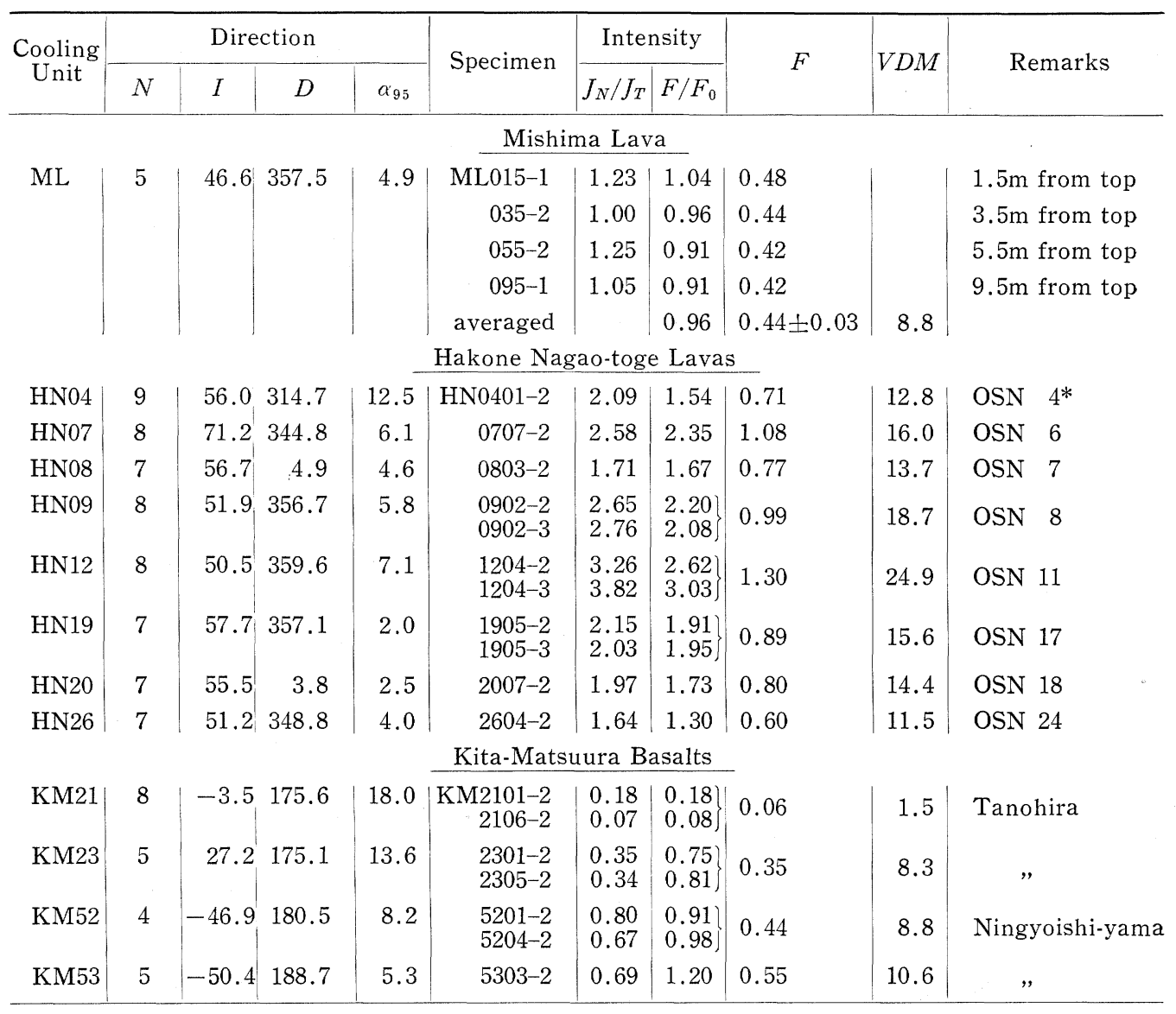

$N:$ number of samples.

$I$ : inclination of NRM after a.c. demagnetization in degrees, downward positive.

$D$ : eastward declination in degrees.

$\alpha_{95}$ : semiaxis of cone of $95 \%$ confidence, in degrees.

$J_{N} / J_{T}$ : ratio of NRM to TRM produced in a field of 0.4610 .

$F / F_{0}$ : ratio of the magnitudes of the past to that of the present geomagnetic field.

$F$ : paleointensity in Oe.

$V D M:$ virtual dipole moment defined by $V D M=\frac{F r^{3}}{2}\left(1+3 \cos ^{2} I\right)^{1 / 2}$ in unit of $10^{25}$ gauss $\mathrm{cm}^{3}$.

*: corresponding unit names in Nagata et al. (1963) and Kono et al. (1964).

\section{Nagao-toge Lavas of Hakone (HN)}

Hakone is a Pleistocene triple volcano composed of double sommas encircling a caldera and seven central cones (Kuno, 1950, 1951). Activity of the old (outer) somma is supposed to have taken place about $0.5 \mathrm{~m}$.y. ago from the paleomagnetic stratigraphy of volcanic rocks in Hakone-Izu volcanic region (Nagata et al., 1957). This view is also in accord with the results of K-Ar dating of Usami Volcano by Kaneoka et al. (1970). It is therefore certain that these samples correspond to Brunhes normal period (Cox, 1969). 
The old somma lavas are exposed in a well developed succession as a caldera wall, especially along the road between Sengokubara and Nagao-toge. The rocks are mainly andesites with small amount of dacitic and basaltic rocks in the top and the lowest layers. It was shown in previous studies that NRM of these lavas is stable with normal polarity and the virtual geomagnetic poles corresponding to each layer are distributed around the present geographic pole (Nagata et al., 1963; Kono et al., 1964). A new set of samples was collected from the same outcrops in 1968 for paleointensity studies.

Thirty-six specimens were studied by Thellier's method. Twelve gave satisfactorily linear $J_{n}-J_{t}$ curves (Fig. 3). In many of these successful $J_{n^{-}} J_{t}$ diagrams, the points corresponding to $500^{\circ} \mathrm{C}$ or higher temperatures do not lie on straight lines. Although the direction of $J_{n}$ component stayed very close to NRM direction below $500^{\circ} \mathrm{C}$, a big deviation of $J_{n}$ direction was observed in every such sample at that temperature. NRM of these rocks is fairly stable to a.c. demagnetization; the direction of NRM did not change more than ten degrees and only about twenty percent of intensity was lost by application of 120 oe field. Therefore, the low temperature $J_{n}$ component rather than the high temperature one should be taken as the stable component of magnetization. The high temperature " $J_{n}$ " may be the result of oxidation of ferromagnetic minerals caused by heating in laboratory (see Kono, 1968). Accordingly these points were omitted in the calculation of paleointensities.
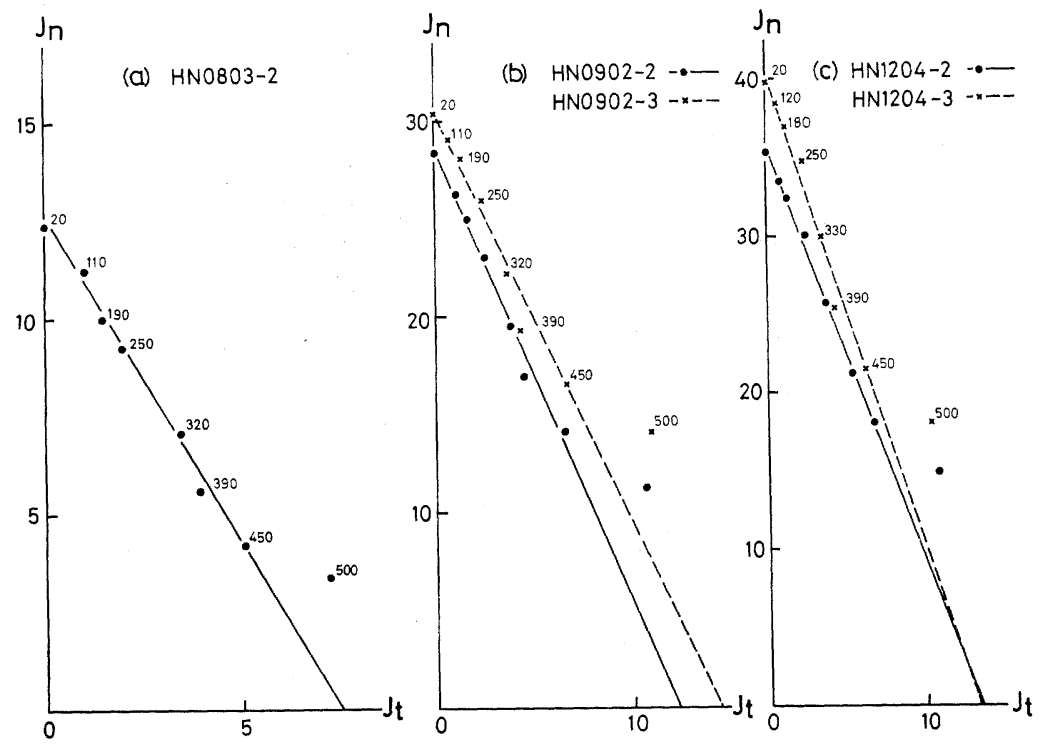

Fig. 3 Examples of $J_{n}-J_{t}$ diagrams of $\mathrm{HN}$ specimens. Numbers in the figure indicate the temperature in ${ }^{\circ} \mathrm{C}$. Intensity unit: $10^{-4} \mathrm{emu} / \mathrm{g}$.

All the paleointensities determined are quite high compared to the present geomagnetic field. Even in the specimens regarded not good enough to yield intensity estimates, this tendency is clearly seen; the initial (low temperature) $J_{n}-J_{t}$ slopes are much larger than unity (corresponding to $F=0.461 \mathrm{Oe}$ ). As the stability of NRM is 
fairly high these initial slopes may not be due to secondary component. They are consistant with the assumption that these rocks are formed when the ambient magnetic field was very strong. Paleointensities determined in some specimens exceed one oersted, which is near the limit of proportionality of TRM with the magnetic field. Coe (1967 b) proposed an empirical method to extend the paleointensity determination to nonlinear region. However, as his method lacks definite theoretical or experimental basis, no correction was attmpted in the present study. Nagao-toge paleointensities can be taken as the lower limit of the true field intensity. Such high paleointensities have only been reported so far for Mesozoic (about 200 m.y.) and for Precambrian (about 1100 and 2500 m.y.) from a study of basic igneous rocks in Canada by Schwarz and Symons (1968). Results are summarized in Table 1 in stratigraphic order (from younger to older).

\section{Shigarami Formation (SG)}

In the northern part of Nagano Prefecture, shallow sea sediments and volcanic rocks deposited during late Miocene and Pliocene forming the so-called Shigarami Formation (Takeshita et al., 1960). Lavas and intrusive rocks, mostly augite-hypersthene andesites, are exposed along the Susobana River. Momose (1963) studied the NRM of these rocks and concluded that they represent a time in Pliocene when the polarity of the geomagnetic field was reversing. He also determined the ratio of NRM to TRM for these rocks and inferred that the field intensity was much reduced in the transition interval. To reexamine his results on paleointensity by Thelliers' method, samples were collected from two normal (Tochinoki-Seto 18 Loc. 5 and Tsubone 17 of Momose, 1963) and three transitional units (East of Doai 9, Hiraidezawa 10 and West of Akefujibashi A 14 of Momose, 1963) in this formation.

All the specimens showed peculiar behaviors to heat treatments. NRM component does not decrease smoothly with thermal demagnetization but increases in some temperature intervals. In several specimens, TRM component also does not increase monotonically when the temperature is raised. It is possible that self-reversal may be occurring in certain temperature range. In $J_{n}-J_{t}$ diagrams, points do not distribute around a single straight line so that no reliable intensity estimates can be obtained. TRM capacity increases very prominently in most specimens by heating to higher than $500^{\circ} \mathrm{C}$. This effect may partly explain the low values of NRM/TRM ratio Momose (1963) obtained from the samples of Shigarami Formation. It is concluded that Shigarami rocks are not appropriate to derive intensity estimates considering their peculiar behaviors to heat treatment and the failure to reproduce the magnetization process in laboratory.

\section{Kita-Matsuura Basalts (KM)}

In northwestern Kyushu, Cenozoic volcanic rocks cover an area of approximately $250 \mathrm{~km}^{2}$. The principal member of rocks is alakali basalt and they are called KitaMatsuura Basalts. On the basis of stratigraphic observation, Kurasawa (1967) concluded that the eruptions of the lavas had occurred over a relatively long period ranging 
from middle Pliocene to early Pleistocene. Samples were taken at Fuefuki, Tanohira and Ningyoishi-yama in Matsuura City and at Tsujinodo-toge in Higashi-Yamashiro Town. Of these, clear lava flow sucessions were found in the latter three sites. Samples from nine lavas at Tsujinodo and Ningyoishi-yama were dated by K-Ar method, with ages in the range 7-10 m.y. and the average being $8.0 \mathrm{~m} . \mathrm{y}$. (Ozima et al., 1968a). Stratigraphic relation among the four sites is not exactly known.

Some of the specimens also showed peculiar $J_{n^{-}} J_{t}$ curves like Shigarami specimens. Every specimen from a lava flow in which the dispersion angle $\alpha_{95}$ of NRM exceeds twenty degrees belongs to this category. In the paleointensities obtained from sufficiently straight $J_{n}-J_{t}$ curves, those from lavas KM21 and KM23 of Tanohira sequence may correspond to intensity of the transition period. The virtual geomagnetic poles for these two layers are situated at $58^{\circ} \mathrm{S}, 138^{\circ} \mathrm{E}$ and $42^{\circ} \mathrm{S}, 136^{\circ} \mathrm{E}$ and are significantly removed from the rotational axis at $95 \%$ confidence level. Also, these two units appear sandwiched between purely normal and purely reversed flows. Results are summarized in Table 1. Cooling units belonging to the same sequence are listed in stratigraphic order.

\section{Discussion and Conclusions}

In the course of the present study, a total of 112 specimens from six volcanic formations were treated by Thelliers' method. Of which, rocks from Hanamagari and Kiruzumi Formations (KH) near Mt. Asama are omitted in the preceding sections as none of the twelve specimens gave any meaningful results (Ozima et al., 1968b). The obtained paleointensities are only 22 corresponding to 13 cooling units (Table 2). This may be the result of inadequate selection of samples especially for the case of Pliocene rocks. Most of $\mathrm{KH}, \mathrm{SG}$ and $\mathrm{KM}$ units are magnetically unstable; i.e., their dispersion

Table 2. Summary of Paleointensity Determination

\begin{tabular}{|c|c|c|c|c|c|c|c|}
\hline \multirow[t]{2}{*}{ Rock Group } & \multirow[t]{2}{*}{ Age } & \multirow{2}{*}{$\begin{array}{c}\text { Number of } \\
\text { Units } \\
\text { (Specimens) } \\
\text { Studied }\end{array}$} & \multirow{2}{*}{$\begin{array}{c}\text { Number of } \\
\text { Unit } \\
\text { (Specimens) } \\
\text { Accepted }\end{array}$} & \multicolumn{2}{|c|}{ Paleointensity (Oe) } & \multicolumn{2}{|c|}{$\begin{array}{l}\text { Virtual Dipole } \\
\text { Moment } \\
\left(10^{25} \text { gauss } \mathrm{cm}^{3}\right)\end{array}$} \\
\hline & & & & Mean & $\begin{array}{l}\text { Standard } \\
\text { Deviation }\end{array}$ & Mean & $\begin{array}{l}\text { Standard } \\
\text { Deviation }\end{array}$ \\
\hline Mishima Lava & Order of $10^{4}$ years & $1 \quad(5)$ & 1 (4) & 0.44 & $\longrightarrow$ & 8.8 & - \\
\hline $\begin{array}{l}\text { Hakone } \\
\quad \text { Nagao-toge lavas }\end{array}$ & $<0.7 \mathrm{~m} . \mathrm{y}$. & $28(36)$ & 8 (11) & 0.89 & 0.19 & 16.0 & 4.2 \\
\hline $\begin{array}{l}\text { Hanamagari } \\
\text { formation }\end{array}$ & 1 m.y. & $3 \quad(3)$ & $0 \quad(0)$ & $\longrightarrow$ & $\longrightarrow$ & & 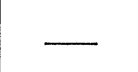 \\
\hline $\begin{array}{l}\text { Kirizumi } \\
\text { formation }\end{array}$ & 3 m.y. & $8 \quad(8)$ & $0 \quad(0)$ & - & 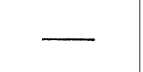 & & - \\
\hline $\begin{array}{l}\text { Shigarami } \\
\text { formation }\end{array}$ & Pliocene & $5(23)$ & $0 \quad(0)$ & - & - & & - \\
\hline $\begin{array}{l}\text { Kita-Matsuura } \\
\text { basalts }\end{array}$ & 8 m.y. & $19(37)$ & $4 \quad(7)$ & 0.35 & 0.21 & 7.3 & 4.0 \\
\hline Total & & $64(112)$ & $13(22)$ & 0.69 & 0.33 & 12.7 & 3.8 \\
\hline
\end{tabular}


angles are very large and big changes occurred in the directions of NRM by a.c. demagnetization. It is clear that rocks which do not give a good convergence of NRM or of which NRM is not stable in a.c. demagnetization will never be appropriate material for paleointensity determination.

The Pliocene paleointensities from KM specimens are, except KM21 which probably corresponds to a transition period, not much different from the magnitude of the present geomagnetic field (the dipole moment is $8.0 \times 10^{25}$ gauss $\mathrm{cm}^{3}$ ) which is in good agreement with the other values for Pliocene (Coe, 1967 a; Kono and Nagata, 1968; Krs, 1968; Sasajima and Maenaka, 1969). Data from Hakone, on the other hand, suggest quite a strong magnetic field compared to the present one. It is quite probable that this high intensity is a characteristic of the geomagnetic field in Brunhes normal epoch. The possible relation between this high intensity of the geomagnetic field and the central magnetic anomalies of mid-ocean ridges will be discussed elsewhere (Kono, 1971).

\section{Acknowledgements}

The author is indebted to Drs. M. Ozima and H. Kinoshita for their criticisms and for comments which resulted in improvement of the manuscript. $\mathrm{He}$ is also grateful to Drs. S. Aramaki, H. Kurasawa and K. Momose and to the late Prof. H. Kuno for their assistance in sampling and in geological interpretation.

\section{References}

Coe, R.S., Paleo-intensities of the earth's magnetic field determined from Tertiary and Quaternary rocks, J. Geophys. Res., 72, 3247-3262, 1967a.

Coe, R.S., The determination of paleo-intensities of the earth's magnetic field with emphasis on mechanism which could cause non-ideal behavior in Thellier's method, J. Geomag. Geoelect., 19, 157-179, $1967 \mathrm{~b}$.

Cox, A., Geomagnetic reversals, Science, 163, 237-245, 1969.

Kaneoka, I., M. Ozima and H. Kuno, Paleomagnetism and K-Ar ages of successive lava flows (4)-K-Ar ages of the Usami Volcano, Izu Peninsula, Japan, J. Geomag. Geoelectr., 22, 559-561, 1970.

Kono, M., Paleomagnetism of Pleistocene Usami Volcano, Izu Penninsula, Japan-Instensity of the earth's magnetic field in geological time II, J. Geomag. Geoelect., 20, 353-366, 1968.

Kono, M., Intensity of the earth's magnetic field in Pliocene and Pleistocene, in relation to the amplitude of mid-ocean ridge magnetic anomalies, Earth Planet. Sci. Lett., 11, 10-17, 1971.

Kono, M. and T. Nagata, Intensity of the earth's magnetic field in geological time I, Late Pliocene in the southwestern U.S.A., J. Geomag. Geoelect., 20, 211-220, 1968.

Kono M., H. Kinoshita, T. Nagata and H. Kuno, Paleomagnetic study of the lave flows of the Hakone Volcanoes, 1964 Ann. Prog. Rept. Rock Mag. Res. Group Japan, 54-59, 1964.

Krs, M., Geomagnetic field intensity during the Plio-Pleistocene derived from the thermoremanence of porcellanites and paleo-slags (Czechoslovakia), Pure Appl. Geophys., 69, 158-167, 1968.

Kuno, H., Geology of Hakone Volcano and adjacent areas, Part I, J. Fac. Sci. Univ. Tokyo, Sec. II, 7, 257279, 1950, Part II, ibid, 351-403, 1951.

Kurasawa, H., Petrology of the Kita-Matsuura basalts in the northwest Kyushu, Southwest Japan, Report 217, pp. 111, Geological Survey of Japan, Tokyo, 1967.

Momose, K., Studies on the variation of the earth's magnetic field during Pliocene time, Bull. Earthq. Res. Inst. 41, 487-534, 1963 . 
Nagata, T., S. Akimoto, S. Uyeda, Y. Shimizu, M. Ozima, K. Kobayashi and H. Kuno, Paleomagnetic studies on a Quaternary volcanic region in Japan, J. Geomag. Geoelect., 9, 23-41, 1957.

Nagata, T., M. Ozima, Y. Syono, M. Ozima, Y. Arai, H. Kinoshita and H. Kuno, Preliminary report on Paleomagnetic study of the lava flow of the Hakone Volcanoes, 1963 Ann. Prog. Rept. Rock Mag. Res. Group Japan, 101-105, 1963.

Ohnaka, M., Stability of remanent magnetization of rocks under compression-its relation to the grain size of rock-forming ferromagnetic minerals, J. Geomag. Geoelect., 21, 495-505, 1969.

Ozima, M., I. Kaneoka, M. Kono, H. Kinoshita, K. Kobayashi, M. Ohnaka, T. Nagata and H. Kurasawa, Paleomagnetism and K-Ar ages of successive lava flows (2) Kita-Matsuura basalt, Kyushu, Japan, J. Geomag. Geoelect., 20, 85-92, 1968a.

Ozima, M., I. Kaneoka, M. Kono, H. Kinoshita, K. Kobayashi, M. Ohnaka, T. Nagata and S. Aramaki, Paleomagnetism and K-Ar ages of successive lava flows (3) Hanamagari and Kirizumi andesites, Gumma Prefecture, Japan, J. Geomag. Geoelect., 20, 101-105, 1968 b.

Sasajima, S. and K. Maenaka, Variation of the geomagnetic field intensity since the late Miocene, J. Geophys. Res., 74, 1037-1044, 1969.

Schwarz, E. J. and D.T.A. Symons, On the intensity of the paleomagnetic field between 100 million and 2500 million years ago, Phys. Earth Planet. Interiors, 1, 122-128, 1968.

Smith, P.J., Ancient magnetic field intensities, I, Geophys. J., 13, 417-419, 1967a, II, ibid., 13, 483-486, 1967b, III, ibid., 16, 457-460, 1968.

Takeshita, H., Y. Saito and K. Momose, Paleomagnetism and volcanic geology of the Shigarami Formation, Chikyu-kagaku, No. 49, 26-36, 1960.

Thellier, E. and O. Thellier, Sur l'intensité du champ magnétique terrestre dans le passé historique et géologique, Ann. Geophys., 15, 285-376, 1959.

Tsuya, H., Geology of Volcano Mt. Fuji, pp. 27 with a geological map, Geological Survey of Japan, Tokyo, 1968. 